\title{
A Review on Gestational Diabetes Mellitus: Present Concern
}

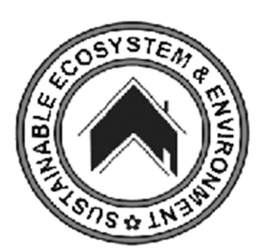

\author{
Kaur, N. ${ }^{1}$, Priyanka ${ }^{2}$, Kaur, P. $^{2}$, Monika ${ }^{1}$
}

Received: 24.03.2021

Revised: 12.05.2021

Accepted: 20.05.2021

\begin{abstract}
Diabetes mellitus during pregnancy known as GDM is a severe disorder that develops during pregnancy and its prevalence is rapidly increasing all around the world. It arises due to two major metabolic defects; acute resistance of insulin and dysfunctioning of beta cells. Numerous organs are additionally associated with the pathological process of GDM. There are two types of factors that are associated with GDM that are modifiable and non-modifiable. GDM can cause serious long-term complications to both fetus and mother due to maternal hereditary proneness linked with the environment and fetoplacental aspects. The purpose of this manuscript is to audit GDM in detail and to provide a logical information with refreshed exploration from various angles.
\end{abstract}

Keywords: Biomarkers, Diabetes, Disease, Gestational, Pregnancy

\section{Introduction}

Gestational diabetes mellitus is most likely recognized as a metabolic ailment of pregnancy and it refers to a kind of intolerance of glucose, noticed during the second and third term of pregnancy promoting hyperglycemia (American Diabetes Association 2016). The scope of diabetes expanded from $4.6 \%$ to $14 \%$ in metropolitan regions and $1.7 \%$ to $13.5 \%$ in rustic zones. Around 62 million individuals are experiencing type 2 diabetes mellitus in India which can augmentation to 79.4 million by 2025. About 4 million people are suffering from GDM in India (Akhalya et al., 2019). Pancreas $\beta$-cells secrete a hormone named Insulin which regulates glucose balance by expanding glucose take-up into peripheral tissues, repressing the liver's ability to produce glucose, and restraint reserve lipid discharge by fat tissue. Insulin opposition is fundamentally characterized as a condition, during these typical insulin range neglect to accomplish suitable natural reaction of the insulin receptor. Therefore, more insulin is released by $\beta$-cells than normal to manage maternal blood glucose levels. At the point when maternal $\beta$ cells don't ready to acclimate to the metabolic changes occurring in pregnancy, GDM happens

\section{Author's Address}

${ }^{1}$ Department of Biotechnology, Mata Gujri College, Fatehgarh Sahib: 140406, India

${ }^{2}$ Department of Food Technology, Mata Gujri College, Fatehgarh Sahib: 140406, India

E-mail.: monika@matagujricollege.org
(Alejandro et al., 2020). The pathophysiology of GDM is associated with hormonal irregular characteristics influencing insulin affectability and pancreatic $\beta$-cell disability (World Health Organization Guideline 2014).GDM further raises the risk of developing type 2 diabetes in both mothers and their infant, and so, to reduce the probability of developing T2D in many generations, balancing of glycemic control during pregnancy is beneficial (Thapa et al., 2014).GDM comprises a more prominent effect on diabetes as it prompts hazard of creating Type 2 diabetes mellitus to mother and offspring subsequently in their living. Furthermore, GDM is also associated with cardiometabolic hazard factors like lipid anomalies, hypertensive problems and hyperinsulinemia which further trigger the advancement of cardiovascular sickness and metabolic syndrome (Dirar, 2017). It is imperative to separate gestational diabetes mellitus from type 2 diabetes mellitus beforehand or during the gestational period. Gestational diabetes mellitus can be characterized by measuring the range of glucose going from 92 milligrams per deciliter starving and in the 60th minutes of the oral glucose resilience test (OGTT) greater than or equal to $180 \mathrm{mg} / \mathrm{dl}$, and greater than equal to 153 milligrams per deciliter in about 120th minutes of OGTT. In the course of parturiency, diabetes mellitus can be examined on the condition when the starving glucose range in the 120th minute of 


\section{Kaur et al.}

OGTT is higher than 125 milligrams per deciliter or greater than or equal to $200 \mathrm{mg} / \mathrm{dl}$ (Rosik et al., 2019). It is indispensable to scan as well as examines DM during pregnancy straightaway in parturiency. This is a typical way of dealing; carry out two screenings for glucose digestion impairment during gestation. The prime examination is carried out when there is a principal visit to a woman's doctor. The particular strategy can be legitimized by newborn, embryonic, and maternal GDM complications (Metzger et al., 2007). Presently various particles, genes, and epigenetic processes are recognized that assume a part in the enhancement of T2DM and go about as potential danger elements of GDM (Rosik et al., 2019).

Glucose mechanism during ordinary pregnancy: During usual pregnancy, the maternal body goes through a sequence of physiological changes to satiate the requirement of the developing fetus such as variations to the cardiovascular, renal and so, however, the salient metabolic transformation is in insulin affectability. During pregnancy, the sensitivity of insulin changes according to the necessities of gestation. Insulin sensitivity inclines during the early period of pregnancy, stimulating glucose take-up into tissues of fat for the vitality requests for the next pregnancy (Di Cianni, 2003). As the gestational period advances, a condition of insulin resistance is advanced by neighborhood and placental hormones that are estrogen, progesterone, leptin, cortisol, placental lactogen as well as growth hormone (Costa, 2016) which leads to increase blood glucose (Catalano et al., 1991) this glucose is moved across the placenta for development of the embryo. This condition of insulin obstruction aid in the endogenous production of glucose and fat breakdown which lead to the elevation in the concentration of glucose in the blood along with free unsaturated fat (Phelps et al., 1981).

\section{Pathophysiology of GDM:}

Gestational diabetes mellitus happens due to an increment in blood hormone level which inhibits insulin resulting in insulin resistance. And another mechanism that leads to the occurrence of GDM is the impairment of pancreatic islet $\beta$-cell. Therefore, dysfunctioning of $\beta$-cell and resistance of insulin are basic elements of the pathological process of GDM (Lambrinoudaki et al., 2010). The purposes of beta-cells are for hold plus to deliver mellitus because of the stress of glucose. When beta cells incapable of distinguishing typical level of glucose present in the blood, or emit insulin likewise, the particular state is known as beta cells disability (Weir et al., 2001) and a huge extent of likely genes which are connected with DM in gestational period is fairly identified with a beta-cell role like potassium potential-gated medium KQT-like 1 (Kcnq1) and glucokinase (Gck) (Prentki, 2006). Beta-cell disability can be further worsened with insulin obstruction. Lower insulin-invigorated glucose take-up additional prompts hyperglycemia, burdening $\beta$-cells, leading to the production of more insulin accordingly (Ashcroft et al., 2017).

When cells are unable to react satisfactorily to the insulin that condition is known as Insulin opposition. Basically, insulin opposition is a condition in which malfunction in the signaling of mellitus, causes glucose transporter 4 (GLUT4) irregular plasma membrane movements which are a prime carrier that is required for glucose transportation into the cell where it can be used as fuel. Conjunctive to it, modified expression or downstream controllers phosphorylation in the signaling pathway of insulin comprising insulin receptor substrate, phosphatidylinositol 3-kinase and Glucose transporter type 4 , is explained in Gestational Diabetes Mellitus (Akhalya et al., 2019). Numerous GDM hazard factors show impacts by meddling with the signaling pathways of insulin such as saturated fatty acids. They incline the diacylglycerol concentration in myocytes hence activate PKC as well as inhibit TEK receptors, insulin receptor substrate, and phosphatidylinositol 3-kinase (Sivan et al., 2003).

In this pathological process of disease of insulin resistance like in GDM, neuro-hormonal defects are also involved. This association drives hunger, dynamic energy usage, and basal metabolic proportion; it is comprised of an intricate organization of focal and peripheral signals (Morton et al., 2006, Thorens, 2008). A portion of adipokines is the prime controller of neurohormonal assimilation restraint as they can be engaged with cell signaling and are essentially delivered by fat tissue which incorporates leptin and adiponectin:Adipocytes basically discharge the hormone known as Leptin. Its role is on neurons within the hypothalamus nucleus which decreases the hunger and slope energy utilization (Farr et al., 
2015). Distortion in blood-brain blockage or via internal processes which is similar to insulin resistance can cause leptin resistance (Koch et al., 2014). At the time when leptin first come into play, leptin was recognized as a suitable cure for treating people with obesity. But it was uncovered that most of the fat and overweight people don't react to leptin, rather exhibit leptin resistance (Hamilton et al., 1995). Adipocytes secrete a hormone which is known as adiponectin. It is created in fat tissues and controls numerous metabolic cycles like lipid digestion, glucose, and unsaturated fat oxidation. The functioning of leptin is, it decreases opposition of insulin, enhances lipid digestion, and have antierythrogenic characteristics (Pawlik et al., 2017). Adiponectin improves signaling of insulin along with oxidation of unsaturated fat, it thwarts gluconeogenesis, this happens by enacting AMPK in cells that are insulin delicate, that support activity of insulin receptor substrate and in the liver, by enacting the transcription factor peroxisome proliferator-activated receptor alpha (PPAR $\alpha$ ) (Kishida et al., 2012). Insulin receptor

substrate starts functioning when insulin binds to the insulin receptor (IR). Adiponectin support insulin receptor substrate actuation through AMPenacted protein kinase which is favorable to provocative cytokines that start PKC employing $\mathrm{I} \kappa \mathrm{B}$ kinase (IKK) that ruins Insulin receptor substrate. phosphatidylinositol-3-kinase (PI3K) is actuated by insulin receptor substrate that phosphorylates phosphatidylinositol-4, 5bisphosphate (PIP2) to phosphatidylinositol-3, 4, 5phosphates. Akt2 is enacted by PIP3 that further improves Glucose transporter type 4 movement and glucose take-up into the cell.

Patients with GDM have decrease adiponectin (Williams et al., 2004). The study was conducted by Lin-ting Huang et al in 2019 for determining the relation between Adiponectin, C1Q, and Collagen Domain Containing polymorphisms in $+45 \mathrm{~T} / \mathrm{G}$, $+276 \mathrm{G} / \mathrm{T}$, and $-11377 \mathrm{C} / \mathrm{G}$ and $\mathrm{GDM}$ threats. Relationship in $+45 \mathrm{~T} / \mathrm{G}$ and GDM was evaluated by nine articles, out of nine studies, eight were performed in Asia and the one in South Africa, involving 1024 Gestational Diabetes Mellitus patients and 1059 controls. The results suggested strong relation between $+45 \mathrm{~T} / \mathrm{G}$ and Gestational DM. Relationship in $+276 \mathrm{G} / \mathrm{T}$ and $\mathrm{DM}$ during pregnancy was evaluated by 5 investigations, involving 590 patients along with 595 references. The result illustrates no association between them. The interconnection among $-11377 \mathrm{C} / \mathrm{G}$ and diabetes mellitus during parturiency threat was determined by 5 analysis, out of which 2 investigations were held in Asia and 2 studies were conducted in Europe and 1 in South America, involving $722 \mathrm{GDM}$ cases and 791 controls. The result showed no association between them (Huang et al., 2019). Organs engaged with the pathophysiology of GDM are adipose tissues, liver, brain, and muscles, etc. Adipose tissues are necessary endocrine organs as they secrete adipokines and cytokines. Obesity, Type 2 DM, and Diabetes Mellitus during pregnancy are linked with a slanted measure of occupant adipose tissue macrophages (ATM) that discharge supportive of provocative cytokines like Tumour necrosis factor $\alpha$, Interleukin 6 , and Interleukin 1 beta. Proerythrogenic cytokines work both to impede the signaling of insulin and discourage insulin discharge from beta cells (Barbour et al., 2007). GDM placentae release fewer pro-inflammatory cytokines than healthy placentae and this was determined by Lappas et al. (2010) through his study. There is some recent proof that microbial organisms present in the gut which is known as gut microbiome might be involved in the development of GDM. It is discovered that the gut microbiome is contrasted among metabolically fit and fat and overweight folks, involving the period of gestation (Barrett et al., 2016). Through the discharge of chemicals and cytokines, the placenta likewise gets included in insulin opposition during pregnancy. The transportation of glucose, lipids, and amino acids can be impacted over the placenta (Augustin, 2010).

\section{Factors that cause GDM:}

The factors that can lead to the possibility of GDM are obesity, strong family background of diabetes, macrosomic infant, preeclampsia, diabetes in a past pregnancy, and maternal age, etc. (Langer et al., 2005). The risk factors are categorized into two groups i.e.

- Modifiable factor

- Non-modifiable factors

Modifiable factors: Metabolic disorders with contemporary diet arrangement which has high-fat 


\section{Kaur et al.}

content, and canned or convenience foods, is purpose behind the event of GDM (Sedaghat et al. , 2017). Furthermore, raised dietary acid strain additionally contributes in developing the risk of GDM (Haghighatdoos et al., 2015). During pregnancy, the intake of macronutrients in the diet may result in the development of GDM (Zhang et al., 2006). But the risk of GDM decreases if a person consumes the diet containing high fiber (Liu et al., 2006); micronutrients also affect glucose tolerance (Bao et al., 2014). Pregnant mothers possibly gain nearly thirty percent of the mass in fatty tissues and overweight are few probable variables for diabetes in pregnancy (De Souza et al., 2015). The consumption of antidepressants and psychotropic drugs, smoking (Hosler et al., 2011), and improper sleep (Myoga et al., 2019) are associated with GDM development. Information about change in worldwide climate has driven to the uplifted interest of effect of climate changes on mankind health. Many pieces of evidences depicted that metabolic function like insulin sensitivity is changed by climate factors like season, ambient temperature, and humidity (U.S. Global Change Research Program 2016, Moses et al., 1997). Recent studies suggested the importance of environmental exposure like toxic metals (Varshavsky et al., 2019), air pollution (Elshahidi 2019), and chemicals (Ehrlich et al., 2016) in the development of GDM. In 2020, the study was conducted by Preston et al., to determine the association between climate factors with GDM. The study for depicting the effect of seasonality on GDM involves the evaluation of twelve studies (Katsarou et al., 2016, Mose et al., 1995, Meek et al., 2020). Most of the studies showed a high predominance of GDM diagnosis in the summer season and fewer incidences in winters (Vasileiou et al., 2018, Molina-Vega et al., 2020). Ambient temperature and GDM association were also determined by evaluating eight studies (Preston et al., 2020). Three studies showed no critical relationship between ambient temperature and GDM but another five studies showed an association between them (Retnakaran et al., 2018, Yogev et al., 2004). Most considered constituents of diabetes in gestation risks are the family foundation of diabetes, hereditary susceptibility, and way of life during pregnancy like eating regimen, active work. But utilization of fossil fuels at an alarming rate for transferring, energy production, or else mankind actions, atmosphere contaminations are one of the prime health issues in many countries (Cohen et al., 2017). Recent studies depicted that wind contamination can likewise contribute to the improvement of type 2 Diabetes Mellitus (Liu et al., 2019, Rao et al., 2015). Somewhat, GDM has the same pathological pathway and physiopathology with T2DM which shows that surrounding air contamination exposure may impact the event of GDM. A study conducted by Zhang in 2020 to provide an overview of air pollution on GDM by evaluating 13 epidemiological studies and air pollutants considered were $\mathrm{SO}_{2}, \mathrm{NO}_{2}$, and $\mathrm{O}_{3}$. The results of studies showed that exposure to $\mathrm{SO}_{2}$ in the first trimester can enhance the GDM risk (Zhang et al., 2020).

Non- modifiable or genetic factors: These factors involve maternal age, a few investigations have shown that mothers with age group over 25-30 years have an increased possibility to develop GDM (Lee et al., 2018). Another factor is a strong family history of diabetes, as it has a solid connection among gene polymorphisms of Type 2 Diabetes and dm during pregnancy (Lauenborg et al., 2009), etc. Relationship between genetics and GDM was proved by many shreds of evidence gathered in the previously conducted studies. The association between T2DM and GDM is found (Ling et al., 2016). Moreover, various genetic polymorphisms in a gene are engaged in insulin discharge, insulin opposition, and glucose digestion, which are correlated to the risk of T2DM, and also enhance the possibility of advancement of GDM (Moon et al., 2017). Studies conducted in previous years predicted that loci present in genes that are important for insulin discharge, insulin opposition, and glucose digestion are linked with GDM risk (Di Cianni et al., 2003). Some genetic polymorphisms or variants associated with GDM are TCF7L2 gene (Transcription factor 7-like 2) which is identified with the discharge of insulin and is located on chromosome10q25.3. This gene variant rs7903146 and rs5030952 were studied as a result two examinations showed a solid relationship between $\mathrm{T}$ allele of rs7903146 variation present in TCF7L2 gene and GDM (Shaat et al., 2007, Watanabe et al., 2007). GCK gene(Glucokinase) gene related to insulin secretion 
and located at position 7p15.3-p15.1 and its variant rs1799884 has been widely investigated. But the result is yet to be determined because two studies showed no relationship between this variant and GDM (Chiu et al., 1994, Allan et al., 1997) but on other hand two studies demonstrate association between the two (Freathy et al., 2010). Another meta-examination portrayed that $\mathrm{T}$ allele of rs1799884 has a solid relationship with GDM hazard (Zhang et al., 2013). Gene KCNJ11 is related to insulin release and is located on chromosome 11p15.1 (Table 1 and 2). The study was performed to investigate the relationship between its variation rs5219 otherwise called E23K with GDM hazard. The results showed an association of rs5219 with GDM (Mao et al., 2012). A multiple-investigation additionally depicted that allele $\mathrm{T}$ of rs5219 was strongly linked in elevating the risk of GDM. CDKAL1 gene was involved in $\beta$-cell function as well as insulin secretion. Its variants rs7754840 and rs7756992 were investigated. Results depicted that polymorphism in these variants can cause GDM (Guo et al., 2013). Another study was conducted among the population of Asia and results disclose that $\mathrm{C}$ allele of rs7754840 is fundamentally connected with GDM (Zhang et al., 2013).IRS1 gene (Insulin receptor substrate 1) these are genes of insulin and insulin receptor and are located on 2q36. This gene is present in tissues that are sensitive to insulin. Moreover, this gene encodes a protein that is responsible for signal transmission from insulin growth factor 1 receptor to intracellular effector protein. Absence of this protein can lead to a disturbance in the pathway that needs IRS1 that can contribute to insulin resistance (Kaburagi et al., 1999). The relationship of IRS1 polymorphism was investigated. The single amino acid Gly972Arg (rs1801278) was responsible for disturbing the insulin secretion and elevate the GDM risk (Florez et al., 2004, Tang et al., 2013). Meta investigations showed: T allele of rs1801278 has a connection with GDM (Zhang et al., 2014). MTNR1B gene (melatonin receptor 1B) is present in pancreatic islets. Basically, the pineal gland produces a hormone melatonin which is a tryptophan derivative (Lyssenko et al., 2009). This gene reduces the cAMP level which further results in insulin secretion and downregulation of GCK expression (Mulder et al., 2009). The effect of two variant polymorphisms was studied i.e. rs 10830963 and rs1387153. The result represented that polymorphism in both variants is linked with GDM risk. The G allele in rs10830963 can lead to GDM (Huang et al., 2019). The 1387153, allele T is more regularly found among patients with GDM (Takeuchi et al., 2010).

Table 1: Genes related to insulin secretion (Dirar et al., 2017)

\begin{tabular}{|l|l|l|l|l|}
\hline SN & Genes & Location & Variants & Association \\
\hline $\mathbf{1}$ & KCNJ11 & $11 \mathrm{p} 15.1$ & E23K & Notable \\
\hline $\mathbf{2}$ & TCF7L2 & $10 \mathrm{q} 25.3$ & rs7903146 & Notable \\
\hline $\mathbf{3}$ & GCK & $7 \mathrm{p} 15.3-\mathrm{p} 15.1$ & rs1799884 (-30G/A) & Notable \\
\hline $\mathbf{4}$ & ABCC8 & $11 \mathrm{p} 15.1$ & $\begin{array}{l}\text { tagGCC allele of exon 16 and the AGG allele of the } \\
\text { R1273R }\end{array}$ & Notable \\
\hline
\end{tabular}

Table 2: Genes of insulin and insulin receptors (Dirar et al., 2017)

\begin{tabular}{|l|l|l|l|l|}
\hline SN & Gene & Location & Variants & Association \\
\hline $\mathbf{1}$ & INSR & $19 \mathrm{p} 13.3-\mathrm{p} 13.2$ & INSR allele-1 Kpn I RFLP & Remarkable \\
\hline $\mathbf{2}$ & IGF2 & $11 \mathrm{p} 15.5$ & IGF2 Bam HI RFLP & Remarkable \\
\hline $\mathbf{3}$ & IGF2BP2 & $3 \mathrm{q} 27.2$ & rs4402960 & Remarkable \\
\hline
\end{tabular}


suffered from this ailment during past partu riency may have episode rehash of GDM in ensuing gestations (Wang et al., 2019). The infant also suffers from short and long-term issues. It leads to malformations. Three interlinked molecular chain reactions are related to inborn distortions and are changed in biological lipid processes, bountiful formation of harmful radicals of superoxide, and initiation customized cell demise. The most frequent abnormalities are in the cardiovascular system which incorporates change of great vessels, ventricular and atrial septal inadequacy, hypoplasia of left ventricle, situs inversus, abnormalities in aortic and complicated cardiac abnormalities (Sovio et al., 2016). The fetus's internal fabrication of insulin and insulin-like growth factor 1 (IGF-1) may be invigorated by the rise in the placenta's transfer of amino acids, glucose, and fatty acids. And combination of this can lead to fetal abundance, coming about in macrosomia upon entering the world (Schwartz et al., 1994). Abundant fetal insulin creation can pressure the maturing beta cells of the pancreas that results in beta cell disability along with the opposition of insulin (Fetita et al., 2006). Shoulder dystocia can be caused by Macrosomia. Therefore, offspring during parturiency with GDM are conveyed through the cesarean procedure. Once conveyed, these children are in danger of hypoglycemia (Gascho et al., 2017).

\section{Biomarkers for the forecast of GDM:}

During Gestational Diabetes mellitus, the deteriorated adipose tissue and placenta release particular, steady and simple for assessing aspects that can cause inflammation, insulin obstruction and the cardiovascular sores. They may be recognized in mother flow and in urine which may be utilized as a device for the expectation of GDM (Almorós et al., 2019). Biomarkers are generally defined as a marker of typical biological metabolic process that can be used to identify ailment or other natural condition of organisms (Dias et al., 2018). Biomarkers comprises of any substance in the body that can be measured and detected easily (Atkinson et al., 2001). The features of ideal biomarkers are that they should be of reasonable cost and reproducible, easily detected through non-invasive methods, sensitive to changes in disease condition, etc (Sahu et al., 2011). Metabolic indicators have been researched as diagnostic devices to perceive ladies in danger of GDM. The first biomarker is Insulin resistance. With the help of homeostasis model assessment (HOMA), raised insulin obstruction during the prime period of gestation is assessed by utilizing starving glucose present in serum and insulin levels, which is connected to GDM hazard (Smirnakis et al., 2005). For instance, Asian Indian ladies at increased hazard of GDM at 24-28 weeks gestation have high insulin opposition in the main trimester of pregnancy was determined. Depiction of insulin sensitivity during the first trimester by using the Matsuda index and HOMA for sensitivity, are found potential indicators of GDM (Grewal et al., 2012). Another one is liver-derived Sex hormone-binding globulin (SHBG). It is a glycoprotein, manifest in the placenta which binds to androgen and estrogen, and acts as a controller of sex steroid chemicals. SHBG has an opposite association with a raised range of insulin in prime and onset of the second period of gestation in ladies that afterwards create GDM (Smirnakis et al., 2007, Corcoran et al., 2018). Reduced plasma SHBG levels are an efficient biomarker for GDM during the first trimester of gestation (Ding et al., 2006). Adipose-derived factors also act as a biomarker as they secrete adipokines like leptin and adiponectin. Specifically, pro-inflammatory adipokine like leptin is associated with immune responses which influence glucose digestion by estranging hunger and insulin activity and activating oxidative stress and arterial stiffness. Leptin can be used as a biomarker as the level of leptin is higher in typical and overweight ladies with later GDM conclusion from the mid-second of gestation (Roca et al., 2012, Boyadzhieva et al., 2013). However, adiponectin is an adipokine that has anti-inflammatory, anti-atherosclerotic, and insulin-sensitizing properties. Adiponectin was revealed to have lower levels along the first- third trimester of GDM incubations. Therefore, the ratio of adiponectin/leptin in plasma is proposed as an indicator of GDM (Thagaard et al., 2017). TNF alpha and CRP also act as predictive biomarkers (table 3). TNF alpha was produced by the placenta and CRP was produced by liver, pancreas, and adipose. These cytokines were increased in plasma of women with GDM during the $1^{\text {st }}, 2^{\text {nd }}$, and $3^{\text {rd }}$ trimester of pregnancy. Syngelaki et al. in their study revealed that maternal TNF alpha is 
A review on Gestational diabetes mellitus: present concern

Table 3: Biomarkers for prediction of GDM (Lorenzo-Almorós et al., 2019)

\begin{tabular}{|l|l|l|}
\hline Protein biomarker & Origin & Changes in GDM \\
\hline SHBG & Liver, placenta & Lower \\
\hline Afamin & Liver, placenta & Higher \\
\hline FABP4 & Adipose, placenta & Higher \\
\hline Adiponectin & Adipose, breast & Lower \\
\hline Omentin-1 & Adipose, placenta & Lower \\
\hline IL-6 & Adipose, lung & Higher \\
\hline TNF $\alpha$ & Macrophages (adipose, placenta) & Higher \\
\hline AHBA & Urine/plasma & Higher \\
\hline
\end{tabular}

Complications caused due to GDM in mother and offspring:

GDM can cause present moment or long haul medical problems in mother. The chances of various types of infections increase in diabetic pregnancies (Akhalya et al., 2019). Women deliver a heavy-weight child which causes increase birth trauma (Dyck et al., 2002). Moreover, women suffering from GDM are more likely to develop T2D (Rayanagoudar et al., 2016). GDM is connected with antenatal depression. Furthermore, it likewise prompts extra pregnancy complications, like preterm birth and preeclampsia, and surgical delivery of the baby (Byrn et al., 2015). In GDM, endothelial cells are damaged due to hyperglycemia which can lead to vascular dysfunction linked with hypertension (Stanley et al., 2011). GDM improves the likelihood of hypertension during pregnancy and in the postpartum period (Sullivan et al., 2011). Diabetes and hypertension both are hazardous factors that lead to the occurrence of pre-eclampsia, a disorder which is portrayed by hypertension and proteinuria (Weissgerber et al., 2015). Hyperglycemia during pregnancy typically resolved after delivery, extended resistance of insulin, and dysfunctioning of $\beta$-cell are seen in GDM patients, continuing beyond pregnancy. Ladies who have associated with GDM in 11-13 weeks of gestation (Kisa et al., 2019).

Placental versus maternal tissues part in gestational diabetes mellitus:

At the beginning of maturation, a synergy of mother mellitus along the syncytiotrophoblast may result in changed cytokines production and secretion that further will follow up on the mother. In the third period of a typical pregnancy, this interchange prompts poor-grade systemic inflammation by expressing a usual set of cytokines. This circumstance deteriorates in pregnancies for women who is an obese and those with GDM (De Castro et al., 2011). Function of the fetoplacental unit in GDM is that the placentaldetermined exosomes accept a capacity of immunomodulation in the mother by restrainment of macrophages and NK cell initiation, as well as enlistment of lymphocyte programmed cell death. They stifle T-signalling parts like CD3- zeta and JAK3. Placenta-derived exosomes have syncytin-1 that intervene in trophoblastic syncytialization and controls cell movement of endothelial, subsequently leading the maternal-fetal circulation. From trophoblasts, secreted exosomes leads to the discharge of pro-irritant cytokines from endothelial cells in GDM patients. This process typically states that inflammatory phenomena are related to GDM. In ladies with overweight and GDM, the placenta contributes to inflammation. During $3^{\text {rd }}$ period of gestation, Women suffering from GDM have a large portion of T-helper 17 cells. These states may change placental process and endocrine activity that leads to the transformation of the placenta, as well as the foetoplacental section will be impacted insulin activity causing GDM. Function of mother fat tissue in GDM is that the complex of neurohormonal control appetite, energy utilization, and basal metabolic rate. By affecting adiposity and glucose expenditure, it gives rise to GDM. The adipokines like adiponectin, leptin, TNF-alpha, and adipocyte fatty acid-binding protein (AFABP), found to be associated with the disturbed physiological processes of GDM. Leptin can repress insulin secretion with help of various pathways such as by decreasing the proinsulin messenger RNA levels under high glucose concentrations in $\beta$-cells; hindrance of glucose movement in beta cells; PI3K-subordinate initiation 


\section{Kaur et al.}

of PDE3B which results in lowering in range of cAMP and further leads to concealment of PKA contributing in the guideline of $\mathrm{Ca} 2+$ channels as well as exocytosis; and retardation of the phospholipase-C/ protein kinase-C process. Increased circulating Adipocyte Fatty Acid-Binding Protein concentrations are found in victims with diabetes mellitus during gestation after changes for adiposity, IR, triacylglycerol, CRP (Berberoglu, 2019).

\section{Treatment of GDM:}

Diagnosis of women suffering from GDM is crucial for the preparation of a management plan focusing to decline both fetal and maternal ailments. The prime motivation behind the treatment is to stabilize the concentration of maternal blood inside a proper reach in a typical pregnancy. During the antenatal period, the management approaches for ladies with GDM include medical nutrition therapy or treatment (MNT), workouts, self-monitoring of blood glucose (SMBG), and if required than pharmacological therapy can also be used. All women diagnosed with GDM should undergo nutritional counseling. The design is to adjust ordinary glycemic control without ketosis and fetal trade-off alongside the support of satisfactory weight acquire dependent on pre-birth BMI (Balaji, 2011). The pattern of meals will give satisfactory calories and supplements to fulfill the requirement of pregnancy. The food pattern should be planned by a dietician in such a way that it should satisfy the least nutrient prerequisites for pregnancy and accomplish glycemic goals without leading to weight loss or excessive weight gain. To fulfill the several necessities, the accompanying dietary standards have been proposed as appropriate for ladies with GDM and they are eating little suppers of gradually assimilated carb to stabilize concentrations of blood glucose; a comparable measure of carb should be taken at meals daily, ingestion of moderate measure of sugar-containing food sources so that neither it may enhance hyperglycemia nor leads to unnecessary weight acquire; consumption of minimum five bits of fruits and vegetables daily (Hill, 2007). For many pregnant ladies with gestational diabetes, work out helpful and suggested. Patients are advised to engage in exercise for 30 minutes many times a week. But, pregnant ladies often require alteration of their activity routine due to musculoskeletal or mechanical manifestations like pubic symphysis disability or back torment. By involving particular exercise within the administration scheme for GDM, might aid women with GDM (Herbert et al., 2010). When the patients are not able to accomplish control on glycemia along with nourishment and work out, insulin pharmacotherapy is suggested as Insulin therapy is safe and effective. Mother weight is the basis to decide insulin dosage. 1 insulin routine portion insulin at $0.7 \mathrm{units} / \mathrm{kg}$ genuine weight of the body. This dose is less for diabetic patients without GDM. Oral agents like Metformin, Glyburide, and Acarbose are also used for the treatment. Metformin is a tablet that is utilized for almost 40 years to serve diabetes. It can be used during pregnancy as a substitute for insulin. Metformin ameliorates insulin sensitivity and is assumed along these lines to refine resilience during gestation by declining the physiologic emergence in insulin opposition which can occur while the gestation period. Metformin is considered safe and lowers the risk of miscarriage and evolution of GDM when utilized for the entire pregnancy. Metformin is also beneficial in addition to insulin injections. Utilizing them together can keep insulin dose lower which assist in the prevention of excessive pregnancy weight gain and therefore enhance pregnancy outcomes. Metformin does pass across the placenta (Muhas et al., 2017).

\section{Conclusion}

To conclude, gestational diabetes mellitus is a critical problem of pregnancy that prompts unfriendly impacts on mother and baby. It is a kind of intolerance of glucose present in the second and third period of gestation bringing about hyperglycemia. Its prevalence is rapidly inclining worldwide. Pathophysiology of GDM is found to be associated with hormonal imbalances, disruption of the pancreatic beta-cell along insulin opposition. Ladies experiencing GDM may be in high danger of developing T2D. Numerous particles, genes, and epigenetic systems are distinguished that assume a part in the advancement of Type 2 Diabetes Mellitus and go about as potential danger variables of GDM. Many organs are further involved in the pathophysiology of GDM like the placenta, gut, liver, brain, etc. GDM is caused by many risk factors that can be modifiable that include climate, 
temperature, and air pollution, etc. and the factors that can be non-modifiable and also known as genetic factors which include maternal age, history, etc. there are many present moment and long haul complexities that are caused due to GDM to both fetus and mother such as increased chances of infection, development of T2D, malformation, abnormalities in the cardiovascular system, etc. after thinking about risk factors, specific predictive biomarkers from distinct stages of GDM pregnancy is used such as elevated insulin obstruction in the main first period of pregnancy, Sex hormonebinding globulin, adipokines like leptin and adinopectin and many more. There is a role of placental and maternal tissues in gestational

\section{References}

Akhalya, K., Sreelatha, S., Rajeshwari and Shruthi, K. 2019. Gestational diabetes mellitus. Endocrinol Metab Int J., 7:26-39.

Alejandro, E.U. and Mamerto, T.P., 2020. Gestational Diabetes Mellitus: A Harbinger of the Vicious Cycle of Diabetes. Int. J. Mol. Sci., 21:5003.

Allan, C.J., Argyropoulos, G., Bowker, M., Zhu, J., Lin, P.M., Stiver, K., Golichowski, A. and Garvey, W.T., 1997. Gestational diabetes mellitus and gene mutations which affect insulin secretion. Diabetes Res ClinPract., 36:135141

American Diabetes Association., 2016. Classification and diagnosis of diabetes. Diabetes Care, Volume 39.

Ashcroft, F.M., Rohm, M., Clark, A. and Brereton, M.F., 2017. Is Type 2 Diabetes a Glycogen Storage Disease of Pancreatic $\beta$ Cells? Cell Metab, 26:17-23.

Atkinson, A.J., Colburn, W.A., DeGruttola, V.G., DeMets, D.L., Downing, G.J., Hoth, D.F., Oates, J.A., Peck, C.C. and Schooley R.T. et al., 2001. Biomarkers and surrogate endpoints: Preferred definitions and conceptual framework. Clin. Pharmacol. Ther, 69:89-95.

Augustin, R., 2010. The protein family of glucose transport facilitators: It's not only about glucose after all. IUBMB Life, 62:315-333.

Balaji, V. and Seshiah, V., 2011. Management of diabetes in pregnancy. JAPI, 59:108-12.

Bao, W., Bowers, K., Tobias, D.K., Olsen, S.F., Chavarro, J., Vaag, A., Kiely, M. and Zhang C., 2014. Prepregnancy low-carbohydrate dietary pattern and risk of gestational diabetes mellitus. The placental-derived exosomes function in maternal immunomodulation, stifle $\mathrm{T}$ signalling components, neurohormonal network in mother, etc. for the management and treatment of GDM, the identification and diagnosis should be done. For the treatment of GDM, various therapies like insulin therapy, and MNT and oral agents like metformin, glyburide and acarbose are used.The ratio of adiponectin/leptin in plasma, TNF alpha and CRP is the best and easy method which can be used to predict the GDM. Avoid- antidepressants and psychotropic drugs, smoking, air pollution, toxic metals, chemical and proper sleeping hours, are the best alternatives to manage GDM other than nutritional one.

diabetes mellitus: A prospective cohort study. Am. J. Clin. Nutr., 99: 378-1384.

Barbour, L.A., McCurdy, C.E., Hernandez, T.L., Kirwan, J.P., Catalano, P.M. and Friedman, J.E., 2007. Cellular mechanisms for insulin resistance in normal pregnancy and gestational diabetes. Diabetes Care, 30:112-119.

Ben-Haroush, A., Yogev, Y. and Hod, M., 2004. Epidemiology of gestational diabetes mellitus and its association with type 2 diabetes. Diabet Med, 21:103-113.

Berberoglu, Z., 2019. Pathophysiology of Gestational Diabetes Mellitus. EMJ Diabet, 7:97-106.

Boyadzhieva, M., Atanasova, I., Zacharieva S. and Kedikova, S., 2013. Adipocytokines during pregnancy and postpartum in women with gestational diabetes and healthy controls. $\boldsymbol{J}$ Endocrinol Invest, 36:944-9.

Byrn, M. and Penckofer, S., 2015. The relationship between gestational diabetes and antenatal depression. J. Obstet. Gynecol. Neonatal Nurs., 44:246-255.

Catalano, P.M., 2014. Trying to understand gestational diabetes. Diabet. Med., 31:273-281.

Chiu, K.C., Go, R.C., Aoki, M., Riggs, A.C., Tanizawa, Y., Acton, R.T., Bell, D.S., Goldenberg, R.L., Roseman, J.M. and Permutt, M.A., 1994. Glucokinase gene in gestational diabetes mellitus: population association study and molecular scanning. Diabetologia, 37:104-110.

Cohen, A.J., Brauer, M., Burnett, R., Anderson, H.R., Frostad, J. and Estep, K., 2017. Estimates and 25-year trends of the global burden of disease attributable to ambient air pollution: an analysis of data from the Global Burden of Diseases Study 2015. Lancet, 389:1907-1918. 
Corcoran, S.M., Achamallah, N., O'Loughlin, J., Stafford, P., Dicker, P., Malone, F.D. and Breathnach, F., 2018. First trimester serum biomarkers to predict gestational diabetes in a high-risk cohort: Striving for clinically useful thresholds. Eur. J. Obstet. Gynecol. Reprod. Biol, 222:712.

Costa, Mariana A., 2016. The endocrine function of human placenta: an overview. Reproductive BioMedicine Online, $32: 14-43$

De Castro, J., Sevillano, J., Marciniak, J., Rodriguez, R., Martín, C.G., Viana, M., Eun-suk, O.H., 2011. Implication of low level inflammation in the insulin resistance of adipose tissue at late pregnancy. Endocrinology, 152:4094-105.

De Souza, L.R. and Berger, H., 2015. First-Trimester Maternal Abdominal Adiposity Predicts Dysglycemia and Gestational Diabetes Mellitus in Mid pregnancy. Diabetes Care, 39:61-64.

Di Cianni, G. and Miccoli, R,. 2003. Intermediate metabolism in normal pregnancy and in gestational diabetes. Diabetes Metab, 19:259-270.

Diagnostic criteria and classification of hyperglycaemia first detected in pregnancy: A World Health Organization Guideline 2014. Diabetes Res. Clin. Pract., 103:341-363.

Dias, S. and Pheiffer, C., 2018. Molecular Biomarkers for Gestational Diabetes Mellitus. Int. J. Mol. Sci, 19:2926.

Ding, E.L., Song, Y., Malik, V.S. and Liu S., 2006. Sex Diferences of endogenous sex hormones and risk of type 2 diabetes: a systematic review and metaanalysis. JAMA, 295:12

Dirar Abdel, H.M. and Doupis, J., 2017. Gestational diabetes from A to Z. World J Diabetes, 8: 489-506.

Dyck, R., Klomp, H., Tan, L.K., Turnell, R.W. and Boctor, M.A., 2002. A comparison of rates, risk factors, and outcomes of gestational diabetes between Aboriginal and non-Aboriginal women in the Saskatoon Health District. Diabetes Care. 25:487-493.

Ehrlich, S., Lambers, D., Baccarelli. A., Khoury, J., Macaluso, M. and Ho, S.M., 2016. Endocrine disruptors: a potential risk factor for gestational diabetes mellitus. $A \boldsymbol{m} \boldsymbol{J}$ Perinatol., 33:1313-8.

Elshahidi, M.H., 2019. Outdoor air pollution and gestational diabetes mellitus: a systematic review and meta-analysis. Iran J Public Health, 48:9.

Etheridge, A., Lee, I., Hood, L., Galas, D. and Wang, K., 2011. Extracellular microRNA: A new source of biomarkers. Mutat. Res., 717:85-90.
Eze, I.C., Hemkens, L.G., Bucher, H.C., Hoffmann, B., Schindler, C. and Kunzli, N., 2015. Association between ambient air pollution and diabetes mellitus in Europe and North America: systematic review and meta-analysis. Environ Health Perspect, 123:381-9.

Farr, O.M., Gavrieli, A. and Mantzoros, C.S., 2015. Leptin applications in 2015: What have we learned about leptin and obesity? Curr. Opin. Endocrinol. Diabetes Obes., 22:353-359.

Fetita, L.S., Sobngwi, E., Serradas, P., Calvo, F. and Gautier, J.F., 2006. Consequences of Fetal Exposure to Maternal Diabetes in Offspring. J. Clin. Endocrinol. Metab, 91:3718-3724.

Florez, J., Sjogren, M., Burtt, N., Orho-Melander, M., Schayer, S., Sun, M. and Groop, L., 2004. Association testing in 9,000 people fails to confirm the association of the insulin receptor substrate-1 G972R polymorphism with type 2 diabetes. Diabetes, 53:3313-3318.

Freathy, R.M., Hayes, M.G., Urbanek, M., Lowe, L.P., Lee, H., Ackerman, C., Frayling, T.M., Cox, N.J., Dunger, D.B., Dyer, A.R., Hattersley, A.T., Metzger, B.E. and Lowe, W.L., 2010. HAPO Study Cooperative Research Group. Hyperglycemia and Adverse Pregnancy Outcome (HAPO) study: common genetic variants in GCK and TCF7L2 are associated with fasting and postchallenge glucose levels in pregnancy and with the new consensus definition of gestational diabetes mellitus from the International Association of Diabetes and Pregnancy Study Groups. Diabetes, 59:2682-2689

Gascho, C.L.L., Leandro, D.M.K., Ribeiro, E., Silva, T. and Silva, J.C., 2017. Predictors of cesarean delivery in pregnant women with gestational diabetes mellitus. Rev. Bras. Ginecol. Obstet, 39:60-65.

Gomez-Arango, L.F., Barrett, H.L., McIntyre, H.D., Callaway, L.K., Morrison, M. and Dekker, N.M., 2016. Connections Between the Gut Microbiome and Metabolic Hormones in Early Pregnancy in Overweight and Obese Women. Diabetes, 65:2214-2223.

Grewal, E., Kansara, S., Kachhawa, G., Ammini, A.C., Kriplani, A., Aggarwal, N., Gupta, N. and Khadgawat, R., 2012. Prediction of gestational diabetes mellitus at 24 to 28 weeks of gestation by using first-trimester insulin sensitivity indices in Asian Indian subjects. Metabolism, 61:715-720.

Guo, F., Long, W., Zhou, W., Zhang, B., Liu, J. and Yu, B., 2018. FTO, GCKR, CDKAL1 and CDKN2A/B gene polymorphisms and the risk of gestational diabetes mellitus: A meta-analysis. Archives of Gynecology and Obstetrics, 298:705-715.

Haghighatdoost, F., Najafabadi, M., Bellissimo, N. and Azadbakht, L., 2015. Association of dietary acid load with 


\section{A Review on Gestational diabetes mellitus: present concern}

cardiovascular disease risk factors in patients with diabetic nephropathy. Nutrition, 31: 697-702.

Hamilton, B.S., Paglia, D., Kwan, A.Y. and Deitel, M., 1995. Increased obese mRNA expression in omental fat cells from massively obese humans. Nat. Med., 1:953-956.

Herbert, G., Sandra, L., Anthony, W. and Arthur, J., 2010. Does exercise have a role in the management of gestational diabetes mellitus? Obstetric Med, 3:133-8.

Hill, A., 2007. Encouraging healthier lifestyles-4. Dietary advise for diabetes in pregnancy. J Fam Health Care 17:117-9.

Hosler, A.S., Nayak, S., and Radigan, A.M., 2011. Stressful events, smoking exposure and other maternal risk factors associated with gestational diabetes mellitus. Paediatr. Périnat. Epidemiol, 25:566-574.

Huang, Bo, Wang, Y.K., Qin, L.Y., Wei, Q., Liu, N., 2019. A functional polymorphism rs 10830963 in melatonin receptor 1B associated with the risk of gestational diabetes mellitus. Bioscience Reports, 39:1-13.

Huang, L.T. and Liao X., 2019. Adiponectin gene polymorphisms and risk of gestational diabetes mellitus: A meta-analysis. World J Clin Cases, 7:572-584.

Kaburagi, Y., Yamauchi, T. and Yamamoto-Honda, R., 1999. The mechanism of insulin induced signal transduction mediated by the insulin receptor substrate family. Endocrine Journal, 46:25-34.

Kansu-Celik, H., Ozgu-Erdinc, A.S., Kisa, B., Findik, R.B., Yilmaz, C. and Tasci, Y., 2019. Prediction of gestational diabetes mellitus in the frst trimester: com-parison of maternal fetuin-A, N-terminal proatrial natriuretic peptide, high-sensitivity C-reactive protein, and fasting glucose levels. Arch Endocrinol Metab, 63:121-7.

Katsarou, A., Claesson, R., Ignell, C., Shaat, N. and Berntorp, K., 2016. Seasonal pattern in the diagnosis of gestational diabetes mellitus in southern Sweden. J Diab Res, 2:1-6.

Kishida, K., Funahashi, T. and Shimomura, I., 2012. Molecular mechanisms of diabetes and atherosclerosis: Role of adiponectin. Endocr. Metab. Immune Disord. Drug Targets, 12:118-131.

Koch, C.E., Lowe, C., Pretz, D., Steger, J., Williams, L.M. and Tups, A., 2014. High-fat diet induces leptin resistance in leptin-deficient mice. J. Neuroendocrinol, 26:58-67.

Lambrinoudaki, I., Vlachou, S. and Creatsas, G., 2010. Genetics in gestational diabetes mellitus: Association with incidence, severity, pregnancy outcome and response to treatment. Current Diabetes Reviews, 6:393-399.

Langer, O., Yogev, Y., Most, O. and Xenakis, E.M., 2005. Gestational diabetes: the consequences of not treating. $\mathbf{A m}$ J Obstet Gynecol, 192:989-997.

Lappas, M., Mitton, A., Mittion, A. and Permezel, M., 2010. In response to oxidative stress, the expression of inflammatory cytokines and antioxidant enzymes are impaired in placenta, but not adipose tissue, of women with gestational diabetes. J. Endocrinol, 204:75-84.

Lauenborg, J. and Grarup, N., 2009. Common type 2 diabetes risk gene variants associate with gestational diabetes. $\boldsymbol{J}$ Clin Endocrinol Metab, 94:145-50.

Lee, K.W., Ching, S.M., Ramachandran, V., Yee, A., Hoo, F.K., Chia, Y.C., Sulaiman, W.A.W., Suppiah, S., Mohamed, M.H. and Veettil, S.K., 2018. Prevalence and risk factors of gestational diabetes mellitus in Asia: A systematic review and meta-analysis. BMC Pregnancy Childbirth, 18:494

Ling, Wu, Long, Cui and Wing, H.T., 2016. Genetic variants associated with gestational diabetes mellitus: a metaanalysis and subgroup analysis. Scientific Reports, 6:30539.

Liu, F., Chen, G., Huo, W., Wang, C., Liu, S and Li, N., et al., 2019. Associations between longterm exposure to ambient air pollution and risk of type 2 diabetes mellitus: a systematic review and meta-analysis. Environ. Pollut., 252:1235-1245.

López-Tinoco. C., Roca, M., Fernández-Deudero, A., GarcíaValero, A., Bugatto, F. and Aguilar-Diosdado, M., 2012. Cytokine profile, metabolic syndrome and cardiovascular disease risk in women with late-onset gestational diabetes mellitus. Cytokine, 58:14-9.

Lorenzo-Almorós, A. and Hang, T. 2019 Predictive and diagnostic biomarkers for gestational diabetes and its associated metabolic and cardiovascular diseases. Cardiovasc Diabetol, 18: 140.

Lyssenko, V., Nagorny, C., Erdos, M., Wierup, N., Jonsson, A., Spégel, P. and Groop, L., 2009 Common variant in MTNR1B associated with increased risk of type 2 diabetes and impaired earlyinsulin secretion. Nature Genetics, $41: 82-88$.

Mao, H., Li, Q., and Gao, S., 2012. Meta-analysis of the relationship between common type 2 diabetes risk gene variants with gestational diabetes mellitus. PLoS One, 7:19.

Meek, C.L., Devoy, B., Simmons, D., Patient, C.J., Aiken, A.R. and Murphy, H.R. 2020. Seasonal variations in incidence and maternal-fetal outcomes of gestational diabetes. Diabet Med, 37:674-80.

Metzger, B.E., Buchanan, T.A., Coustan, D.R., de Leiva, A., Dunger, D.B., Hadden, D.R., and Zoupas, C., 2007. 


\section{Kaur et al.}

Summary and recommendations of the Fifth Internatio nal Workshop-Conference on Gestational Diabetes Mellitus. Diabetes Care, 30:251-260.

Molina-Vega, M., Gutiérrez-Repiso, C., Muñoz-Garach, A., Lima-Rubio, F., Morcillo, S. and Tinahones, F.J., 2020. Relationship between environmental temperature and the diagnosis and treatment of gestational diabetes mellitus: an observational retrospective study. Sci Total Environ, 744:1-6.

Moon, J.H., Kwak, S.H. and Jang, H.C., 2017. Prevention of type 2 diabetes mellitus in women with previous gestational diabetes mellitus. Korean Journal of Internal Medicine, 32:26-41.

Morton, G.J., Cummings, D.E., Baskin, D.G., Barsh, G.S. and Schwartz, M.W., 2006. Central nervous system control of food intake and body weight. Nature, 443:289-295.

Moses, R. and Griffiths, R., 1995. Is there a seasonal variation in the incidence of gestational diabetes? Diab Med 12:563-5.

Moses, R.G., Patterson, M.J., Regan, J.M., Chaunchaiyakul, R., Taylor, N.A. and Jenkins, A.B., 1997. A non-linear effect of ambient temperature on apparent glucose tolerance. Diabetes Res ClinPract, 36:35-40.

Muhas, C. and Naseef, P., 2017. A review article-gestational diabetes mellitus. International Journal of Current Pharmaceutical Research, 9:1-5

Mulder, H., Nagorny, C., Lyssenko, V. and Groop, L., 2009. Melatonin receptors in pancreatic islets: Good morning to a novel type 2 diabetes gene. Diabetologia, 52:1240-1249.

Myoga, M., Japan Environment and Children's Study, Tsuji, M., Tanaka, R., Shibata, E., Askew, D.J., Aiko, Y., Senju, A., Kawamoto, T. and Hachisuga, T., 2019. Impact of sleep duration during pregnancy on the risk of gestational diabetes in the Japan environmental and Children's study (JECS). BMC Pregnancy Childbirth, 19:1-7.

Pawlik, A., Teler, J., Maciejewska, A., Sawczuk, M., Safranow, K. and Dziedziejko, V., 2017. Adiponectin and leptin gene polymorphisms in women with gestational diabetes mellitus. J Assist Reprod Genet, 34:511-516

Phelps, R.L., Metzger, B.E. and Freinkel, N., 1981 Carbohydrate metabolism in pregnancy: XVII. Diurnal profiles of plasma glucose, insulin, free fatty acids, triglycerides, cholesterol, and individual amino acids in late normal pregnancy. Am. J. Obstet. Gynecol, 140:730-736.

Plows, J.F. and Stanley, J.L., 2018. The Pathophysiology of Gestational Diabetes Mellitus. Int. J. Mol. Sci, 19:3342

Prentki, M. and Nolan, C.J., 2006. Islet beta cell failure in type 2 diabetes. J. Clin. Investig., 116:1802-1812.
Preston, E.V and Eberle, C., 2020. Climate factors and gestational diabetes mellitus risk - a systematic review. Environmental Health, 19:112.

Radha, V., Kanthimathi, S., Anjana, R. M. and Mohan, V., 2016. Genetics of gestational diabetes mellitus. The Journal of Pakistan Medical Association, 66:11-14.

Rajagopalan, S. and Brook, R.D., 2012. Air pollution and type 2 diabetes: mechanistic insights. Diabetes, 61:3037-3045.

Rao, X., Montresor-Lopez, J., Puett, R., Rajagopalan, S. and Brook, R.D., 2015. Ambient air pollution: an emerging risk factor for diabetes mellitus. CurrDiab Rep, 15:603.

Rayanagoudar, G., Hashi, A.A., Zamora, J., Khan, K.S., Hitman, G. and Thangaratinam, S., 2016. Quantification of the type 2 diabetes risk in women with gestational diabetes: A systematic review and meta-analysis of 95,750 women. Diabetology, 59:1403-1411.

Retnakaran, R., Ye, C., Kramer, C.K., Hanley, A.J., Connelly, P.W. and Sermer, M., 2018. Impact of daily incremental change in environmental temperature on beta cell function and the risk of gestational diabetes in pregnant women. Diabetologia, 61: 2633-42.

Rosik, J. and Szostak, B., 2019. The role of genetics and epigenetics in the pathogenesis of gestational diabetes mellitus. Ann Hum Genet, 84:114-124.

Sahu, P., Pinkalwar, N., Dubey, R.D., Paroha, S., Chatterjee, S. and Chatterjee, T., 2011. Biomarkers: An emerging tool for diagnosis of a disease and drug development. Asian J. Res. Pharm. Sci, 1:9-16.

Schwartz, R., Gruppuso, P.A., Petzold, K., Brambilla, D., Hiilesmaa, V. and Teramo, K.A., 1994. Hyperinsulinemia and macrosomia in the fetus of the diabetic mother. Diabetes Care, 17:640-648.

Sedaghat, F. and Akhoondan, M., 2017. Maternal Dietary Patterns and Gestational Diabetes Risk: A Case-Control Study. J. Diabetes Res, 3:1-8

Shaat, N., Lernmark, A., Karlsson, E., Ivarsson, S., Parikh, H., Berntorp, K. and Groop, L., 2007. A variant in the transcription factor 7-like 2 (TCF7L2) gene is associated with an increased risk of gestational diabetes mellitus. Diabetologia, 50:972-979.

Sivan, E. and Boden, G., 2003. Free fatty acids, insulin resistance, and pregnancy. Curr. Diabetes Rep, 3:319-322.

Smirnakis, K.V., Martinez, A., Blatman, K.H., Wolf, M., Ecker, J.L. and Thadhani, R., 2005. Early Pregnancy Insulin Resistance and Subsequent Gestational Diabetes Mellitus. Diabetes Care, 28:1207-1208.

Smirnakis, K.V., Plati, A., Wolf, M., Thadhani, R. and Ecker, J.L., 2007. Predicting gestational diabetes: Choosing the 
optimal early serum marker. Am. J. Obstet. Gynecol, 196:410.e1-410.e7.

Sovio, U., Murphy, H.R. and Smith, G.C., 2016. Accelerated Fetal Growth Prior to Diagnosis of Gestational Diabetes Mellitus: A Prospective Cohort Study of Nulliparous Women. Diabetes Care, 39:982-987.

Stanley, J., Cheung, C.C., Rueda-Clausen, C., Sankaralingam, S., Baker, P.N. and Davidge, S.T., 2011. Effect of Gestational Diabetes on Maternal Artery Function. Reprod. Sci, 18:342-352.

Sullivan, S.D., Umans, J.G. and Ratner, R.E., 2011. Gestational Diabetes: Implications for Cardiovascular Health. Curr. Diabetes Rep, 12:43-52.

Takeuchi, F., Katsuya, T., Chakrewarthy, S., Yamamoto, K., Fujioka, A., Serizawa, M. and Kato, N., 2010. Common variants at the GCK, GCKR, G6PC2-ABCB11 and MTNR1B loci are associated with fasting glucose in two Asian populations. Diabetologia, 53:299- 308 .

Tang, Y., Han, X., Sun, X., Lv, C., Zhang, X., Guo, W. and Ji, L., 2013. Association study of a common variant near IRS1 with type 2 diabetes mellitus in Chinese Han population. Endocrine, 43:84-91.

Thagaard, I.N., Krebs, L., Holm, J.C., Lange, T., Larsen, T. and Christiansen, M., 2017. Adi-ponectin and leptin as frst trimester markers for gestational diabetes mellitus: a cohort study. ClinChem Lab Med, 55:1805-12.

Thapa, A. and Chitkara, E., 2014. Gestational Diabetes Mellitus. Indian Journal of Basic and Applied Medical Research, 3:275-280.

Thorens, B., 2008. Glucose sensing and the pathogenesis of obesity and type 2 diabetes. Int. J. Obes, 32:62-71.

U.S. Global Change Research Program (USGCRP). 2016. The Impacts of Climate Change on Human Health in the United States: A Scientific Assessment. Washington, DC: U.S. Global Change Research Program.

Varshavsky, J., Smith, A., Wang, A., Hom, E., Izano, M. and Huang, H., 2019. Heightened Susceptibility: A Review of How Pregnancy and Chemical Exposures Influence Maternal Health. Reproductive toxicology, 92:14-56.

Vasileiou, V., Kyratzoglou, E., Paschou, S.A., Kyprianou, M. and Anastasiou, E., 2018. The impact of environmental temperature on the diagnosis of gestational diabetes mellitus. Eur J Endocrinol, 178:209-14
Wang, Y.Y., Liu, Y., Li, C., Lin, J., Liu, X.M., Sheng, J.Z. and Huang, H.F., 2019. Frequency and risk factors for recurrent gestational diabetes mellitus in primiparous women: A case control study. BMC Endocr. Disord, 19:1-7.

Watanabe, R.M., Allayee, H., Xiang, A.H., Trigo, E., Hartiala, J., Lawrence, J.M. and Buchanan, T.A., 2007. Transcription factor 7-like 2 (TCF7L2) is associated with gestational diabetes mellitus and interacts with adiposity to alter insulin secretion in Mexican Americans. Diabetes, $56: 1481-1485$

Weir, G.C., Laybutt, D.R., Kaneto, H., Bonner-Weir, S. and Sharma, A., 2001. Beta-cell adaptation and decompensation during the progression of diabetes. Diabetes, 50:154-159.

Weissgerber, T. and Mudd, L.M., 2015. Preeclampsia and diabetes. Curr. Diabetes Rep, 15:9-579.

Williams, M.A., Qiu, C., Muy-Rivera, M., Vadachkoria, S., Song, T. and Luthy, D.A., 2004. Plasma adiponectin concentrations in early pregnancy and subsequent risk of gestational diabetes mellitus. J Clin Endocrinol Metab, 89:2306-2311.

Zhang, C., Bao, W., Rong, Y., Yang, H., Bowers, K., Yeung, E. and Kiely, M., 2013. Genetic variants and the risk of gestational diabetes mellitus: a systematic review. Hum Reprod Update, 19:376-390.

Zhang, C., Liu, S., Solomon, C.G. and Hu, F.B. 2006. Dietary Fiber Intake, Dietary Glycemic Load, and the Risk for Gestational Diabetes Mellitus. Diabetes Care, 29:22232230 .

Zhang, C., Schulze, M.B., Solomon, C.G. and Hu, F.B., 2006. A prospective study of dietary patterns, meat intake and the risk of gestational diabetes mellitus. Diabetologia, 49:2604-2613.

Zhang, H. and Wang, Q., 2020. Ambient air pollution and gestational diabetes mellitus: A review of evidence from biological mechanisms to population epidemiology. Science of the Total Environment, 719:137349.

Zhang, Y., Sun, C.M., Hu, X.Q. and Zhao, Y., 2014. Relationship between melatonin receptor $1 \mathrm{~B}$ and insulin receptor substrate 1 polymorphisms with gestational diabetes mellitus: A systematic review and meta-analysis. Scientific Reports, 4:6113. 